and supersonic flow, and appear to behave in a remarkably similar way to those at low speeds (Fig. 1). The work shown included detailed quantitative explorations in a low-speed tunnel and flow visualization exporiments on a wing oscillating in a water tunnel in which qualitative observations were being made on the flow in these dynamic conditions.

Results were also displayed from an extensive series of investigations into the aerodynamic design of swept wings for aircraft to cruise in the Mach number range $0 \cdot 8-1 \cdot 2$. A special design of wing section has been doveloped to delay the drag rise that occurs at transonic speeds, and methods of combining a high drag-rise Mach number with a large drag-rise/buffet margin are being sought. To enable drag-rise and buffet boundaries to be predicted, a semi-empirical theory has been developed for calculating pressure distributions in two-dimensional transonic flow. The effects of wing planform, camber and twist have also been studied, together with the design of the junction between wing and fuselage, with the object of maintaining the full sweep of the isobars over the whole of the wing span. One of the biggest problems is to reduce the required body 'waisting' to an amount acceptable for civil aireraft.

Research displayed on boundary-layer and shear flows included theoretical and experimental investigations into the mechanics of transition following the non-linear growth of small disturbances, measurements of surface friction, and studies of turbulent boundary-layer development, wall jets, pipe flow, and the flow up an abrupt step at a Mach number of $2 \cdot 5$.

As part of a long-term programme of research into ship vibration, the Ship Division demonstrated apparatus for determining the characteristics of the oscillatory pressure distribution around model propellers. A large dynamometer for propellers up to 24 in. in diameter measures torque and thrust electrically by movement of a balanced armature transformer, connected to a bearing in a helical slot on the shaft in one case, and to a flexible coupling allowing only axial movement in the other. A new 12-in. open dynamometer was also displayed: this has a capacity of $5 \mathrm{lb} . / \mathrm{ft}$. torque and $50 \mathrm{lb}$. thrust at 0 to 2,000 r.p.m., torque being measured by balancing the reaction on the motor casing, and thrust by balancing the axial load on the shaft. Both components are measured by dead-weight and spring systems, recording on a built-in chart recorder.

On the Lithgow water tunnel, techniques for automatic data recording and analysis have been installed. Measurements of the physical quantities are converted into either rotation of a shaft or into voltages : shaft digitizers or digital voltmeters then turn these into coded electrical pulses suitable for feeding to computers.

\title{
THE BRITISH GLASS INDUSTRY RESEARCH ASSOCIATION
}

\section{NEW LABORATORIES}

$\mathrm{T}$ HE official opening of the newly built laboratories of the British Glass Industry Research Association by the Right Hon. the Earl of Halifax, chancellor of the University of Sheffield, which took place on June 6, marked a noteworthy stage in the development of industrial research for the British glass industry. Co-operative research has been continuously expanding since the inauguration by W. E. S. Turner of a Department of Glass Manufacture in the University of Sheffield in the autumn of 1915. Prof. Turner, then a lecturer in chemistry in the University, pioneered the establishment of a centre of organized scientific research into the physical and chemical properties of glass, to provide technical and scientific advice to the industry, and to include facilities for teaching. Under his influence and professorship (he occupied the chair from its inauguration in 1920 until his retirement in 1945) the Department of Glass Technology, as it was renamed, became known and respected throughout the world by those interested in the manufacture and use of glass.

In his early endeavour to found the Department of Glass Manufacture, Turner received great encouragement from his professor, the late W. P. Wynne, who loaned him a small chemical laboratory for his investigations and a tiny attic to house his glass-melting furnace. He also received the enthusiastic support of glass manufacturers-particularly those of south Yorkshire and of Lancashire. With increase of work and staff, Turner expanded his Department to occupy first a section of the applied science building of the University, and when this became insufficient, the site of a derelict glassworks in the Attercliffe district of the eity. The latter site was occupied until 1938 when, with the financial support of the glass industry, the present Department was built by addition to a large house occupying extensive grounds adjoining the main University territory.

After the Second World War it became apparent that the requirements of industrial investigations, and that part of the research work which formed their immediate background, involved so much time that staff could not efficiently conduct them coincidentally with teaching and long-term research duties. Prof. H. Moore, who succeeded Prof. Turner on his retirement in 1945 , therefore advocated the establishment of a research association as a separate entity, the function of which would be to attack the industrial and development problems, leaving the University Department free to concentrate upon fundamental research and the education of glass technologists. On the retirement of Prof. Moore in 1955 this plan was adopted, Prof. R. W. Douglas being appointed to the chair of glass technology, and Dr. R. G. Newton as director of the newly formed Research Association. From this time until the oceupation of its new building in January 1959, the Research Association's staff was successfully accommodated in the University Department's building, despite the rapid expansion of both organizations. The foregoing will have indicated the close connexion between the University, the Research Association and the glass industry: the new buildings of the Research Association, built to the design of Prof. Stephen Welsh, now stand adjacent to the University Department, which will enable the close connexions of the past to be maintained in the future. 


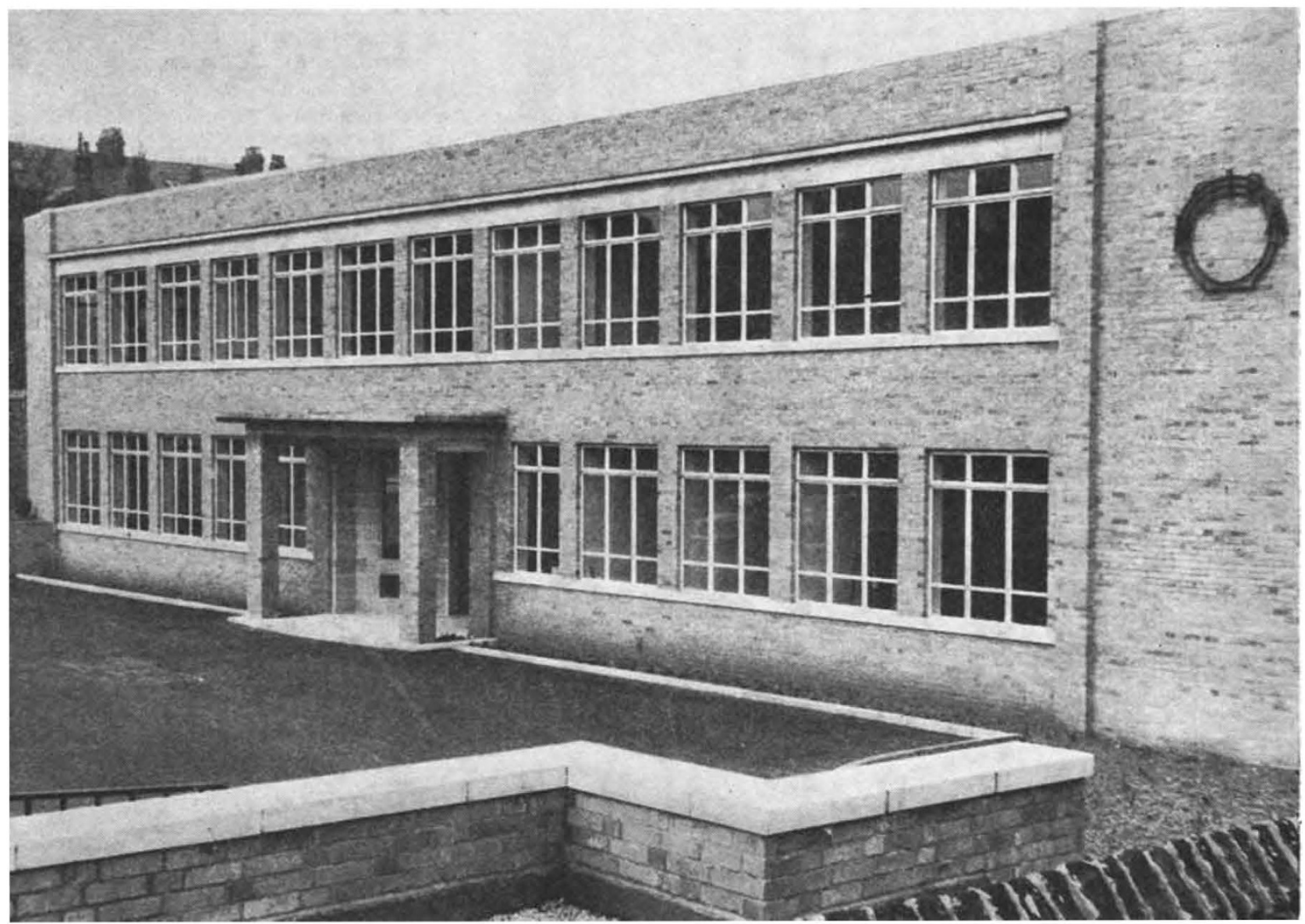

Fig. 1. The British Glass Industry Research Association Laboratories

The British Glass Industry Research Association is supported by eighty-nine subscribing member firms, forty-seven of which are engaged in glass melting, the remainder being closely associated with glass manufacture through the supply of raw materials or are connected with the manipulation of fabricated glass, as, for example, the formation of articles from glass tubing. The strong backing of the British Class Industry Research Association by industry is denoted not only by the fact that approximately half its income is derived from members' subscriptions but also from the fact that the forty-seven members previously noted as being concerned with the actual melting of glass together melt 98 per cent of the total glass melted in the United Kingdom. Strong financial support is also provided to the Association by the Department of Scientific and Industrial Research.

Following the opening ceremony, nombers and guests of the Association were invited to tour the new building and inspect numerous exhibits which illus. trated the type of work being carried out by the Research Association. The laboratories are sectionalized to conform so far as possible with the type of problem to be dealt with. The two-story building, which has a total superficial area of $20,000 \mathrm{sq}$. ft., is of ' $L$ '-shaped plan, the ground-floor housing administrative offices, a section dealing with fuel, furnace and instrumentation problems, laboratories for the study of glass technological problems, a refractories section, and a furnace room with its associated batch mixing shop. The furnace room is sited at the extreme end of the wing and occupies a single story only so that heat and noise will not impede the work of other sections. The first floor is occupied by a reference library and information section, with associated reading rooms and meeting room, work study section, drawing office, and with the physical and chemical laboratories. Each of the latter two sections is subdivided into main and subsidiary laboratories. In the chemical section, for example, a separate division has been made to enable the durability of glass to various attacking media to be studied without the influence of the general atmosphere of the main chemical laboratory. Muffes and lead-lined fume cupboards for decomposition with hydrofuoric acid have also been segregated, and a separate division for spectrographic work has been provided.

A semi-basement extending beneath approximately half the ground-floor area contains an excellently equipped workshop, a pot room and a pot. drying-room for the manufacture of small melting pots and other refractory articles. The remainder of the basement area is given to storage space, boilerhouse, and a glass grinding, cutting and polishing unit.

Numerous demonstrations illustrating the type of work done by individual sections were presented, of which only a limited number may be mentioned within the compass of this short review. The fuel, furnace and instrumentation section demonstrated methods of surface temperature measurement and the estimating and recording of oxygen content of waste gas from furnaces, together with results of furnace heat surveys carried out at member-firms' factories with the view of assessing furnace perform. ance under varying conditions. The physics section demonstrated laboratory apparatus for the determ- 
ination of tensile strength and thermal expansion, the latter by instrumental recording of the rate of expansion, thus eliminating the necessity for lengthy periods of direct observation. This section also demonstrated a pressure test rig for glass panels in which deflexions from fifty individual points on the glass surface were simultaneously displayed on scale instruments and cine-photographed at second inter. vals during the loading cycle. The performance of different types of refractory materials for glass furnace construction had been the subject of investigation by the refractories section, and a demonstration of a corrosion-erosion test rig was given. The glass technology section showed a novel rotating hearth furnace designed to give identical thermal treatment simultaneously to a number of experimental glass batch mixtures. This apparatus is to be used for study of the influence of raw materials on the rate of founding of glass. The chemical section, in addition to numerous examples of analytical techniques in silicate analysis, demonstrated apparatus for the determination of the durability of glass to aqueous attack, and gave an excellent demonstration of the analysis of gaseous inclusions in glass. The demon stration showed methods of extraction of minute bubbles of gas from solid glass and of their analysis to the component gases carbon dioxide, carbon mon- oxide, sulphur dioxide, sulphur trioxide and oxygen. Such studies have an important bearing on the problem of melting high-quality glass at maximum rate. The work-study section illustrated the use of one-second interval cine-photography for the study of manual operators in factories, and has shown that this technique can prove of value when a number of individual manual operations have to be co-ordinated with each other or with the operation of a machine.

Speakers at the official luncheon marking the opening ceremony reviewed the origin and future objectives of the British Glass Industry Research Association. Dr. L. H. A. Pilkington, chairman of the Council of the Association, directed attention to the man-power deployed on research in glass technology at the present time, estimating this to be some 200-250, and forecasting that the figure would increase to 750-900 within a five-year period. Although smaller in numbers than a force of some 750 at present employed in research by four of the largest glass manufacturing firms of the United States, these men managed to keep us abreast of developments in many fields and definitely ahead in some. Mr. A. W. Clark, chairman of the Glass Manufacturers' Federation, referred to the value of research associations to smaller firms the resources of which could not justify individual research units.

\section{COIL SPRING FEDERATION RESEARCH ORGANISATION}

\section{NEW LABORATORIES}

\begin{abstract}
HE Coil Spring Federation Research Organisation, which has been in existence for fourteen years, has for the majority of this time confined its research activities to extra-mural work in universities, although the long-term aim of the spring industry has always been to operate its own research and development laboratories while maintaining the close links it has established with univorsities. This has now boen achieved by the setting up of a new research centre, the construction of which has been financed from reserves set aside for the purpose.

The two-story laboratory block recently completed in Doncaster Street, Sheffield, is probably the most comprehensive of its kind for research into all forms of springs and spring materials.

The ground floor, in addition to the usual reception facilities, contains laboratories for heavy-fatigue testing, general mechanical testing, experimental heat treatment and electroplating. In the fatigue testing laboratory are housed $12 \frac{1}{2}$ h.p. machines capable of applying a dynamic load of 9 tons, which are used for fatigue testing heavy coil springs; up to eighteen springs may be tested at one time. Other machines used for fatigue testing springs of the internal combustion engine type are capable of infinitely variable speeds of compression of up to 4,000 per min. Fatigue tests in repeated torsion are carried out on torsion bars, and are used to produce data from which an assessment of the effects of composition, heat treatment and surface condition can be made prior to the manufacture of experimental helical springs. A special feature of this laboratory is the sound-proofing and anti-vibration features incorporated in both the suspended ceiling and the floor.
\end{abstract}

The mechanical testing laboratory houses a variety of conventional machines used for determining the properties of both specimens and springs, covering the range of material diameters $0.004-2 \cdot 0$ in. One machine, for example, is capable of devoloping a maximum torque of 120,000 in. $1 b$., and is used to investigate the effects of hardenability on the static torsional properties of large-diameter spring steel bars.

Many researches relate to the load-deflexion characteristics of springs and the Organisation has a comprehensive range of machines, capable of applying static loads from a few ounces up to 30 tons. The determination of fatigue characteristics of drawn wires of diameters $0 \cdot 01-0.25 \mathrm{in}$. is provided for by high-speed rotating-beam fatigue machines, which ean complete up to 100 million cycles in as little time as one week. The study of corrosion and protection of spring materials and the effects of hydrogen embrittlement due to electroplating has had an important place in the Organisation's programme for many years. The work is being continued in a new laboratory specially fitted out for this purpose; the plant in it has been presented by Messrs. Canning, Ltd., the Birmingham manufacturers of electroplating equipment. Facilities are available for electroplating copper, zine, tin, cadmium and nickel. The experimental heat-treatment laboratory is equipped with fully instrumented electric furnaces for general heat treatment, and high-temperature heat treatment, under various types of protective atmosphere.

The laboratories contain a number of machine tools and a shot-peening unit which automatically rotates the object under treatment while at the same 